\title{
Pharmaceutical cost and multimorbidity with type 2 diabetes mellitus using electronic health record data
}

\author{
Carla Sancho-Mestre ${ }^{1}$, David Vivas-Consuelo ${ }^{1 *}$, Luis Alvis-Estrada², Martin Romero ${ }^{3}$, Ruth Usó-Talamantes ${ }^{4}$ \\ and Vicent Caballer-Tarazona ${ }^{1}$
}

\begin{abstract}
Background: The objective of the study is to estimate the frequency of multimorbidity in type 2 diabetes patients classified by health statuses in a European region and to determine the impact on pharmaceutical expenditure.

Methods: Cross-sectional study of the inhabitants of a southeastern European region with a population of 5,150,054, using data extracted from Electronic Health Records for 2012. 491,854 diabetic individuals were identified and selected through clinical codes, Clinical Risk Groups and diabetes treatment and/or blood glucose reagent strips. Patients with type 1 diabetes and gestational diabetes were excluded. All measurements were obtained at individual level. The prevalence of common chronic diseases and co-occurrence of diseases was established using factorial analysis.
\end{abstract}

Results: The estimated prevalence of diabetes was $9.6 \%$, with nearly $70 \%$ of diabetic patients suffering from more than two comorbidities. The most frequent of these was hypertension, which for the groups of patients in Clinical Risk Groups (CRG) 6 and 7 was $84.3 \%$ and $97.1 \%$ respectively. Regarding age, elderly patients have more probability of suffering complications than younger people. Moreover, women suffer complications more frequently than men, except for retinopathy, which is more common in males. The highest use of insulins, oral antidiabetics $(\mathrm{OAD})$ and combinations was found in diabetic patients who also suffered cardiovascular disease and neoplasms. The average cost for insulin was $153 €$ and that of OADs $306 €$. Regarding total pharmaceutical cost, the greatest consumers were patients with comorbidities of respiratory illness and neoplasms, with respective average costs of 2,034.2€ and 1,886.9€.

Conclusions: Diabetes is characterized by the co-occurrence of other diseases, which has implications for disease management and leads to a considerable increase in consumption of medicines for this pathology and, as such, pharmaceutical expenditure.

Keywords: Diabetes mellitus, Pharmaceutical expenditure, Multiborbidity

Abbreviations: CRG, Clinical Risk Groups; CV, Comunidad Valenciana; CVD, Cerebrovascular Disease; DM, Diabetes Mellitus; EDC, Episode Disease Categories; EHR, Electronic Health Record; ICD-9-MC, International Classification of Disease, $9^{\text {th }}$ Revision, Clinical Modification; KMO, Kaiser-Meyer-Olkin; MDC, Major Diagnostic Categories; OAD, Oral Antidiabetics; PIS, Population Information System; SQL, Structured Query Language; T2D, Type 2 Diabetes;

WHO, World Health Organization

\footnotetext{
* Correspondence: dvivas@upvnet.upv.es

${ }^{1}$ Research Centre for Health Economics and Management, Universitat

Politècnica de València, Edificio 7J, Cno de Vera s/n., 46022 Valencia, Spain

Full list of author information is available at the end of the article
} 


\section{Background}

Diabetes is regarded as an epidemic by The World Health Organization (WHO) and is one of the non-contagious chronic diseases with greatest socio-economic impact [1]. In Spain, the prevalence of diabetes is estimated to be around $10 \%$ [2]. Worldwide, diabetes-related health expenditure accounted for $11 \%$ of the total health expenditure for 2011 [3].

Diabetes, like the majority of non-contagious chronic diseases, is associated with multimorbitity, defined in the growing literature as the existence of two or more chronic conditions $[4,5]$. Multimorbidity causes a negative impact on both clinical and health indicators and primary health care costs $[6,7]$. While true that the analysis of multimorbidity in this type of population is relatively new, the tendency towards this approach to the study of chronic diseases is ever increasing $[8,9]$.

This co-occurrence of diseases has implications from a disease management point of view, as the features of comorbid diseases can be much more complicated than a simple aggregation of individual illnesses [10]. Previous studies have related diabetes to a set of diseases such as cardiovascular, renal, obesity and the metabolic syndrome [11-13].

In this research we use the Clinical Risk Groups (CRG) patient grouping system to identify the diabetic patient and the comorbidity [14-17] CRG is a relatively new system that classifies individuals into mutually exclusive categories, using medical contact or consultation data. Each patient is assigned a severity level according to his/her chronic health conditions. CRGs classify the individual and all the medical services used over a determined period of time. There are 1,079 basic CRGs, all of which can be classified into the CRG core health status that maintain clinical significance and take into account future medical attention needs and the clinical similarities of the individuals assigned to the CRGs. The CRG core health status are: 1) healthy; 2) 4 significant acute disease; 3) single or multiple minor chronic disease; 4) moderate chronic diseases; 5) dominant chronic diseases; 6) Chronic disease in 2 or more organ systems 7) multiple dominant chronic diseases; 8) metastatic malignancies; and 9) catastrophic conditions. These basic groups can be aggregated into three levels (ACRG) with each successive level maintaining the health states and severity, while reducing the number of groups and, if necessary, adjusting the severity level. This grouping system gives a morbidity population pattern.

This study aims to estimate the most common multimorbidities in patients with type 2 diabetes (T2D) and their impact on pharmaceutical expenditure in primary health care using health electronic record data.

\section{Methods \\ Objective}

The objective of the study is to estimate the frequency of multimorbidity in type 2 diabetes patients classified by health statuses in a European region and to determine the impact on pharmaceutical expenditure.

\section{Study population}

The study was carried out in the Comunidad Valenciana $(\mathrm{CV})$ in eastern Spain, working with the population for 2012. The total resident population for that year was $5,150,054$, from which information was taken on 491,854 patients diagnosed with diabetes, being treated with antidiabetics and/or blood glucose reagent strips. Patients with juvenile diabetes, gestational diabetes and those not receiving pharmacological treatment were excluded, reducing the group to 350,015 patients.

\section{Data}

The study was a cross sectional observational study. The data were obtained retrospectivity from the Electronic Health Record (EHR) and the Electronic Prescriber system (GAIA) corresponding to patients attended during the period January to December of 2012. Each patient has a healthcare identification number in the Population information System (PIS). Cases were identified from the population morbidity database (SCP-cv) of the Directorate General of Pharmacy of the Valencian Community Government Health Department (Conselleria de Sanitat). The population was organized and grouped using CRG. This model makes an initial classification which groups International Classification of Disease, $9^{\text {th }}$ revision, clinical modification (ICD-9-MC) diagnostic codes in Major Diagnostic Categories (MDC). 350,015 people were selected as classified in MDC 101 Diabetes Mellitus (DM) from the ICD-9-MC codes of 250.x0 assigned in their medical encounters in 2012 from a CV total of 5,150,054.

Each MDC group's different episode disease categories (EDC) also made up from CIE-9-MC codes. It is considered that EDC 427 Diabetes identifies patients with T1D and EDC 424 Diabetes those with T2D. The chronic conditions (EDCs) analyzed in the study as comorbid were: hypertension, dyslipidemia, mental disorders, osteoarticular disease, cardiovascular and cerebrovascular disease (CVD), thyroid disorders, severity obesity, osteoporosis, COPD, cancer, renal disease, Alzheimer, asthma and pulmonary embolism. CVD and Renal failure were included as comorbid still being an event produced by diabetes complications however not being the only cause. For example, a patient diagnosed with diabetes would be in different levels of severity according to comorbidities and complications. A patient with diabetes but without any other associated chronic pathology would be in status 5 . Another patient with add 
on dominant chronic condition, such as hypertension, would be in status 6 .

To determine which comorbidities should be considered in this analysis, a review of previous literature was conducted. In addition, we established a consensus with specialists in internal medicine.

Other microvascular diabetes related complications were identified from EHR using codes 205.x2 except for codes 250.10 and 250.12 (indicative of TD2 with ketoacidosis and a condition close associate with T1D) similar to the algorithm proposed by Kho et al. [18]. Nephropathy results are not included here due to them having been insufficiently recorded.

Our algorithm was developed with primarily data warehouse, easily accessed through Structured Query Language (SQL).

\section{Analysis}

From the data obtained, we estimated the frequency of episodes of the chronic diseases in the cohort of patients with T2D selected and classified in CRGs. To study the prevalence of other chronic diseases, we adapt the methodology previously reported by other authors [8]. Following Barnet et al., we display frequencies, percentages and cross tabulations for descriptive analysis. Furthermore, we conduct a binary logistic regression to examine associations between physical and mental health comorbidities. We further add a factorial analysis to study prevalence of common chronic diseases and co-occurrence of diseases and include CRG groups in the descriptive analysis.

An exploratory factor analysis was performed with a varimax rotation applied with the aim of identifying the multimorbidity clusters. Factor analysis is one of the most widely used techniques in building models of multimorbidity $[19,20]$, although clinical criteria such as grouping by affected organ systems are also pertinent [21, 22].

The EDCs were coded in binary format (i.e., $0=$ no disease and $1=$ presence of the disease).

The factor analysis was based on a correlation matrix to determine which diagnostic variables comprised each factor [19]. The factors obtained from this analysis were interpreted as multimorbidity patterns. Pharmaceutical use and expenditure were also analyzed bearing in mind the resulting multimorbidity groups. Specifically, we analyzed the use of insulins, oral antidiabetics (OAD) - secretegogues and non-secretegogues - and diabetes test strips, as well as the average cost of these medicines and the total primary health care pharmaceutical expenditure, taking into account the multimorbidity factors obtained.

The incidence of diabetic related microvascular complications (retinopathy, nephropathy and neuropathy) were estimated grouped according to age and gender. Logistic regression identified the effect of gender and age groups (independent variables) on the coexistence of such complications. Pearson chi 2 test was performed to observe the differences between gender and we reported $P$ value under 0.05 were considered statistically significant.

The data used was analyzed using the statistics packet SPSS version 20.0. To comply with the data protection law, an anonymous and irreversibly dissociated number replaced the patient's Healthcare Identification Number (PIS). This observational study was also approved by the Behavioural Research Ethics Board of the Generalitat Valenciana.

\section{Results}

\section{Population description}

Taking the total population of people diagnosed with diabetes in the EHR, the estimated gross prevalence in the $\mathrm{CV}$ for T2D is $9.6 \%$, with an average age of 67.4 years. $51.9 \%$ of the population are male (Table 1 ).

Most of patients have diabetes-related comorbidities, mainly hypertension $(68 \%)$ and comorbidities not related to diabetes (mental disorders: $25.05 \%$ ) (Table 1).

Regarding multimorbidity, $10 \%$ of the diabetic patients suffered from diabetes only, while $70 \%$ suffered from more than 2 comorbidities. The pharmaceutical expenditure shows a clearly rising trend corresponding to the increase in comorbidities (Table 2).

Table 1 Number of people with comorbidities, average pharmaceutical expenditure 2012

\begin{tabular}{lll}
\hline Variable & Number & Percent \\
\hline Male & 181,658 & $51.9 \%$ \\
Female & 168,357 & $48.1 \%$ \\
Total & 350,015 & $100 \%$ \\
T2D Comorbidities related & & \\
Hypertension & 239,611 & $68.46 \%$ \\
Dyslipidemia & 186,574 & $53.30 \%$ \\
Severe obesity & 27,270 & $7.79 \%$ \\
T2D Comorbidities Unrelated & & \\
Mental disorders & 87,673 & $25.05 \%$ \\
Osteoarticular disease & 85,920 & $24.55 \%$ \\
Thyroid disorders & 27,702 & $7.91 \%$ \\
Osteoporosis & 25,861 & $7.39 \%$ \\
COPD & 25,561 & $7.30 \%$ \\
Cancer & 22,792 & $6.51 \%$ \\
Alzheimer & 14,300 & $4.09 \%$ \\
Asthma & 11,120 & $3.18 \%$ \\
Pulmonary embolism & 964 & $0.28 \%$ \\
Complications & & \\
Cardiovascular and cerebral disease & 50,567 & $14.45 \%$ \\
Renal failure & 22,496 & $6.43 \%$ \\
Retinopathy & 25,594 & $7.31 \%$ \\
Neuropathy & 10,984 & $3.14 \%$ \\
\hline & & \\
\end{tabular}


Table 2 Number of people with comorbidities, average pharmaceutical expenditure 2012

\begin{tabular}{lllll}
\hline $\begin{array}{l}\text { Number of } \\
\text { comorbidities }\end{array}$ & Total & N & $\begin{array}{l}\text { Average } \\
\text { pharmaceutical } \\
\text { cost }(€)\end{array}$ & $\begin{array}{l}\text { (standard } \\
\text { deviation) }\end{array}$ \\
\cline { 2 - 5 } Single & 35,644 & $10.18 \%$ & $592.30 €$ & $850.10 €$ \\
One additional & 73,232 & $20.92 \%$ & $887.80 €$ & $1,008.90 €$ \\
Two additional & 94,618 & $27.03 \%$ & $1,189.60 €$ & $1,076.60 €$ \\
Three additional & 72,610 & $20.74 \%$ & $1,531.10 €$ & $1,239.80 €$ \\
Four additional & 41,505 & $11.86 \%$ & $1,881.60 €$ & $1,371.00 €$ \\
Five additional & 19,619 & $5.61 \%$ & $2,221.50 €$ & $1,532.90 €$ \\
Six and more & 12787 & $3.65 \%$ & $3,825.41 €$ & $1,802.90 €$ \\
additional & & & & \\
\hline
\end{tabular}

Differentiating the population of diabetics according to Core Health Status of CRG, it was observed that as the health of the patient worsens, the prevalence of comorbidities increases, in particular hypertension, dyslipidaemia and cardiovascular disease. Specifically, for Health Statuses CRG 5 to 7 the prevalence of hypertension oscillates between $47.5 \%$ - $97.1 \%$, while that of dyslipidaemia ranges from $50.9 \%$ to $59 \%$. For Health Status CRG 8, the prevalence of cancer and hypertension is notable, while for CRG 9 renal disease and hypertension are greater (Table 3 ).

\section{Multimorbidity characteristics and pharmaceutical expenditure}

The factor analysis identifies 6 factors which explain $49.3 \%$ of the variance. The Kaiser-Meyer-Olkin (KMO) statistics value was 0.60 and Bartlett's test of sphericity was less than $5 \%$.

The resulting factors were: cardiovascular (hypertension, dyslipidaemia, cardiovascular disease and renal disease), osteoarticular (osteoporosis and osteoarticular disease), mental (mental disorders and Alzheimer), respiratory (asthma and COPD), metabolic (thyroid disorders and obesity) and neoplasms (cancer and pulmonary embolism) (Table 4).

Analyzing pharmaceutical use in diabetic patients according to multimorbidity clusters, uniformity was observed. Diabetic test strips is the most used technology in diabetic patients. Secretagogue OADs are the most used in patients with cardiovascular, osteoarticular and metabolic factors (Table 5).

The highest average expenditure on insulin is for those belonging to the metabolic factor, equivalent to $146.6 €$. The highest average expenditure on secretagogue OADs corresponds to the osteoarticular factor, at $16.4 €$. For nonsecretagogue OADs the highest expenditure was also on patients in the metabolic factor, at $239.6 €$. Patients in the metabolic factor also had the highest average cost

Table 3 Prevalence of comorbidity and events in the diabetic population according to Core Health Status of CRG. 2012

\begin{tabular}{|c|c|c|c|c|c|c|c|c|c|c|c|c|c|c|c|c|}
\hline Chronic conditions & $\begin{array}{l}\text { CRG } 1 \text { to } \\
4(n)\end{array}$ & $\%$ & $\begin{array}{l}\text { CRG } \\
5(n)\end{array}$ & $\%$ & $\begin{array}{l}\text { CRG } \\
6(n)\end{array}$ & $\%$ & $\begin{array}{l}\text { CRG } \\
7(n)\end{array}$ & $\%$ & $\begin{array}{l}\text { CRG } \\
8(n)\end{array}$ & $\%$ & $\begin{array}{l}\text { CRG } \\
9(n)\end{array}$ & $\%$ & & & & \\
\hline$(E D C)$ & & & & & & & & & & & & & TOTAL & $\%$ & MALE & FEMALE \\
\hline \multicolumn{17}{|c|}{ T2D Comorbidities related } \\
\hline Hypertension & 17,738 & 38.8 & 48,659 & 47.5 & 140,918 & 84.3 & 26,982 & 97.1 & 3,728 & 74.7 & 1,586 & 75.4 & 239,611 & $68.46 \%$ & 117,981 & 121,630 \\
\hline Dyslipidemia & 16,402 & 35.9 & 52,082 & 50.9 & 97,985 & 58.7 & 16,490 & 59.4 & 2,473 & 49.5 & 1,142 & 54.3 & 186,574 & $53.30 \%$ & 96,982 & 89,592 \\
\hline Severe obesity & 2,006 & 4.4 & 6,028 & 5.9 & 15,647 & 9.4 & 3,021 & 10.9 & 374 & 7.5 & 194 & 9.2 & 27,270 & $7.79 \%$ & 11,423 & 15,847 \\
\hline \multicolumn{17}{|c|}{ T2D Comorbidities Unrelated } \\
\hline Mental disorders & 6,208 & 13.6 & 18,449 & 18 & 49,564 & 29.7 & 11,070 & 39.9 & 1,742 & 34.9 & 640 & 30.4 & 87,673 & $25.05 \%$ & 33,274 & 54,399 \\
\hline $\begin{array}{l}\text { Osteoarticular } \\
\text { disease }\end{array}$ & 5,610 & 12.3 & 18,972 & 18.5 & 50,860 & 30.4 & 8,957 & 32.2 & 1,151 & 23.1 & 370 & 17.6 & 85,920 & $24.55 \%$ & 29,324 & 56,596 \\
\hline Thyroid disorders & 2,941 & 6.4 & 7,245 & 7.1 & 14,528 & 8.7 & 2,447 & 8.8 & 381 & 7.6 & 160 & 7.6 & 27,702 & $7.91 \%$ & 5,058 & 22,644 \\
\hline Osteoporosis & 1,234 & 2.7 & 4,072 & 4 & 17,326 & 10.4 & 2,655 & 9.6 & 356 & 7.1 & 218 & 10.4 & 25,861 & $7.39 \%$ & 2,427 & 23,434 \\
\hline COPD & 735 & 1.6 & 2,386 & 2.3 & 10,186 & 6.1 & 10,964 & 39.5 & 1,010 & 20.2 & 280 & 13.3 & 25,561 & $7.30 \%$ & 18,307 & 7,254 \\
\hline Cancer & 688 & 1.5 & 2,382 & 23 & 12,652 & 7.6 & 2,159 & 7.8 & 4,667 & 93.5 & 244 & 11.6 & 22,792 & $6.51 \%$ & 13,639 & 9,153 \\
\hline Alzheimer & 447 & 1 & 1,661 & 16 & 6,556 & 3.9 & 5,350 & 19.3 & 236 & 4.7 & 50 & 2.4 & 14,300 & $4.09 \%$ & 4,928 & 9,372 \\
\hline Asthma & 661 & 1.4 & 1,590 & 16 & 6,932 & 4.1 & 1,717 & 6.2 & 151 & 3 & 69 & 3.3 & 11,120 & $3.18 \%$ & 3,381 & 7,739 \\
\hline $\begin{array}{l}\text { Pulmonary } \\
\text { embolism }\end{array}$ & 33 & 0.1 & 104 & 1 & 482 & 0.3 & 237 & 0.9 & 93 & 1.9 & 15 & 0.7 & 964 & $0.28 \%$ & 433 & 531 \\
\hline \multicolumn{17}{|l|}{ Complications } \\
\hline $\begin{array}{l}\text { Cardiovascular and } \\
\text { cerebral disease }\end{array}$ & 1,463 & 3.2 & 7,415 & 7.2 & 26,688 & 16 & 13,192 & 47.5 & 1,215 & 2.43 & 594 & 28.2 & 50,567 & $14.45 \%$ & 31,135 & 19,432 \\
\hline Renal disease & 1,088 & 2.4 & 3,233 & 32 & 10,104 & 6 & 5,322 & 19.2 & 727 & 146 & 2,022 & 96.1 & 22,496 & $6.43 \%$ & 12,504 & 9,992 \\
\hline
\end{tabular}


Table 4 Factor analysis. Loading with values $> \pm 0.3$

\begin{tabular}{|c|c|c|c|c|c|c|}
\hline \multirow{3}{*}{ Variables } & \multicolumn{6}{|c|}{ Rotated Component Matrix } \\
\hline & \multicolumn{6}{|c|}{ Component } \\
\hline & 1 & 2 & 3 & 4 & 5 & 6 \\
\hline Hypertension & .635 & & & & & \\
\hline Dyslipidemia & .596 & & & & & \\
\hline Cardiac vascular disease & .540 & & & & & \\
\hline Renal disease & .423 & & & & & \\
\hline Osteoporosis & & .715 & & & & \\
\hline Osteoarticular disease & & .639 & & & & \\
\hline Alzheimer & & & .806 & & & \\
\hline Mental disorders & & & .559 & & & \\
\hline Asthma & & & & .722 & & \\
\hline Respiratory illness & & & & .708 & & \\
\hline Severe obesity & & & & & .676 & \\
\hline Thyroid disorders & & & & & .607 & \\
\hline Cancer & & & & & & .740 \\
\hline Pulmonary embolism & & & & & & .584 \\
\hline
\end{tabular}

in diabetic strips at $246.3 €$. The group of patients in the respiratory factor showed the highest average total pharmaceutical expenditure of $2123.1 €$ (Table 5).

\section{Analysis of diabetes microvascular complications}

The prevalence of patients with $\mathrm{T} 2 \mathrm{D}$ with microvascular complications with retinopathy (7.31 \%), and neuropathy $(3.64 \%)$. Renal failure $(6.43 \%)$ and patients with cardiovascular and cerebrovascular disease (14.45\%).
In the logistic regression the microvascular complications are related to the age and gender of the patients. All the variables were significant. The reference is the man of less than 40 years of age. From the logistic regression we obtain some conclusions: regarding to gender, women present lower probability than men of suffering retinopathy, and more probability of suffering the rest of the complications. Regarding age; older patients, presents a higher probability of suffering all of the complications mentioned (Table 6).

\section{Discussion}

In this study, both the prevalence of diabetes and the comorbidities are based on information from the EHR and not from other sources usually used in cross sectional studies. The use of the EHR for automated and subsequent analysis of patients with DM2 is not novel, and a base of evidence is beginning to be built on this. Some authors have published similar algorithms to our system that allow automatic identification of diabetic patients.

Klompas et al. showed that using EHR data for automated diabetes surveillance was feasible and of great potential utility. By taking advantage of the complete data offered by EHRs, including laboratory test results and prescriptions as well as diagnosis codes, an increase can be achieved in both the sensitivity and detail of the surveillance over the use of diagnosis codes alone. Using an integrated algorithm, including laboratory, prescription, and ICD-9 criteria, more patients with diabetes are captured than when using any one criterion alone [23].

Regarding to the prevalence of patients who Suffered DM microvascular complications: first, retinopathy (7.31 \%),

Table 5 Frequency of medicine use and average pharmaceutical cost by multimorbidity groups

\begin{tabular}{|c|c|c|c|c|c|c|c|}
\hline \multirow{2}{*}{$\begin{array}{l}\text { Medicine } \\
\text { Insulins }\end{array}$} & \multicolumn{2}{|l|}{ Factor 1 Cardiovascular } & \multirow{2}{*}{$\begin{array}{l}\text { Factor } 2 \\
\text { Osteoarticular (\%) } \\
6.5 \%\end{array}$} & \multirow{2}{*}{$\begin{array}{l}\text { Factor } 3 \\
\text { Mental (\%) } \\
7.8 \%\end{array}$} & \multirow{2}{*}{$\begin{array}{l}\text { Factor } 4 \\
\text { Respiratory (\%) } \\
8.2 \%\end{array}$} & \multirow{2}{*}{$\begin{array}{l}\text { Factor } 5 \\
\text { Metabolic } \\
(\%) \\
7.5 \%\end{array}$} & \multirow{2}{*}{$\begin{array}{l}\text { Factor } 6 \\
\text { Neoplasm } \\
(\%) \\
8.3 \%\end{array}$} \\
\hline & N (\%) & $6.8 \%$ & & & & & \\
\hline \multirow[t]{2}{*}{ Insulins } & Pharmaceutical expenditure $(€)$ & 122.4 & 118.1 & 133.5 & 139.9 & 146.6 & 125.6 \\
\hline & (standard deviation) & $(307.1)$ & $(298.7)$ & $(314.3)$ & $(330.2)$ & $(361.5)$ & $(296.7)$ \\
\hline Secretagogue OADs & N (\%) & $32.9 \%$ & $32.5 \%$ & $31.7 \%$ & $30.5 \%$ & $32.8 \%$ & $30.9 \%$ \\
\hline \multirow[t]{2}{*}{ Secretagogues } & Pharmaceutical expenditure $(€)$ & 16.0 & 16.4 & 15.3 & 14.5 & 14.7 & 15.2 \\
\hline & (standard deviation) & $(24.0)$ & $(24.6)$ & $(23.2)$ & $(22.9)$ & $(22.0)$ & $(23.9)$ \\
\hline Nonsecretagogue OADs & N (\%) & $10.9 \%$ & $10.6 \%$ & $10.3 \%$ & $10.4 \%$ & $10.5 \%$ & $10.2 \%$ \\
\hline Non & Pharmaceutical expenditure $(€)$ & 226.2 & 213.5 & 206.3 & 202.0 & 239.6 & 191.1 \\
\hline secretagogues & (standard deviation) & $(362.6)$ & $(352.4)$ & (349.3) & $(342.3)$ & $(415.3)$ & $(328.8)$ \\
\hline Strips & N (\%) & $31.5 \%$ & $31.8 \%$ & $33.9 \%$ & $31.7 \%$ & $32.5 \%$ & $37.0 \%$ \\
\hline \multirow[t]{2}{*}{ Strips } & Pharmaceutical expenditure $(€)$ & 222.8 & 227.8 & 235.6 & 241.4 & 246.3 & 225.1 \\
\hline & (standard deviation) & $(192.7)$ & $(192.8)$ & $(200.2)$ & $(203.4)$ & $(217.0)$ & $(191.5)$ \\
\hline \multirow[t]{2}{*}{ Average total cost } & Pharmaceutical expenditure $(€)$ & $1,441.0$ & $1,645.5$ & $1,816.7$ & $2,123.1$ & $1,540.6$ & $1,968.9$ \\
\hline & (standard deviation) & $(1,290.4)$ & $(1,357.0)$ & $(1,570.6)$ & $(1,590.1)$ & $(1,421.9)$ & $(1,685.8)$ \\
\hline
\end{tabular}


Table 6 Logistic regressions of diabetes-related complications adjusted according to age and gender

\begin{tabular}{|c|c|c|c|c|c|c|}
\hline & \multicolumn{2}{|c|}{ Diabetic Nephropathy } & \multicolumn{2}{|c|}{ Diabetic Neuropathy } & \multicolumn{2}{|c|}{ Retinopathy } \\
\hline & OR & $P$ value & $\mathrm{OR}$ & $P$ value & OR & $P$ value \\
\hline \multicolumn{7}{|l|}{ Gender } \\
\hline Females & 0.23 & 0.00 & 0.17 & 0.00 & -0.09 & 0.00 \\
\hline \multicolumn{7}{|l|}{ Age bands } \\
\hline Range 40-44 & 0.32 & 0.00 & 0.55 & 0.00 & 0.33 & 0.00 \\
\hline Range 44-49 & 0.42 & 0.00 & 0.87 & 0.00 & 0.52 & 0.00 \\
\hline Range 50-54 & 0.39 & 0.00 & 1.00 & 0.00 & 0.59 & 0.00 \\
\hline Range 55-59 & 0.54 & 0.00 & 1.05 & 0.00 & 0.69 & 0.00 \\
\hline Range 60-64 & 0.57 & 0.00 & 1.16 & 0.00 & 0.80 & 0.00 \\
\hline Range 65-69 & 0.76 & 0.00 & 1.21 & 0.00 & 0.91 & 0.00 \\
\hline Range 70-74 & 0.91 & 0.00 & 1.27 & 0.00 & 0.91 & 0.00 \\
\hline Range 74-79 & 1.01 & 0.00 & 1.47 & 0.00 & 0.90 & 0.00 \\
\hline Range 80-84 & 1.18 & 0.00 & 1.47 & 0.00 & 0.80 & 0.00 \\
\hline Range 85 and over & 1.17 & 0.00 & 1.38 & 0.00 & 0.61 & 0.00 \\
\hline Reference (Male <40) & -4.22 & 0.00 & -4.75 & 0.00 & -3.27 & 0.00 \\
\hline
\end{tabular}

$O R$ Odds ratio. Statistically significant subgroups are those with $P$ value $<0.05$

whose prevalence is very similar to that of other authors (7.8 \%) but far from the Pantalone et al. (3.4\%) [24]. The second complication was the neuropathy (3.64\%) with a prevalence above the indicated by Alonso Moran et al. [25] $(1.3 \%)$ and below that of Pantalone (18\%). Finally, the prevalence of nephropathy was also a lower figure (3.14\%) to that of the Alonso Moran et al. (8 \%) [26].

The main contribution of this study is the relation between diabetes co-morbidity and pharmaceutical expenditure. The relationship with the CRG patient classification system, a clear trend in the increase of pharmaceutical consumption was observed with the more serious health states. In the case of the analyzed population, multimorbidity was present in nearly all cases, which is consistent with the results of other studies [3, 16, 24, 27, 28] and similar to that of Giralt [29].

Regarding the demographic profile of the population (gender and age) findings were very similar to previous studies [25]. In comparison with other studies, as the age increases the likelihood of suffering complications also increases [30].

The highest pharmaceutical cost implications are connected to mental factors, being higher than that of other factors such as cardiovascular, metabolic and the osteoarticular. This is consistent with recent evidence indicating that the presence of one or more mental comorbidities in people with diabetes may increase the cost from 15 to $94 \%$ [31].

The results were similar to those reported by Huber, which is US \$ 857 for diabetes alone, US \$ 1,298 for the presence of comorbidity, and US \$1,795 for the presence of two comorbidities. The percentage of people with comorbidities increases, two of those percentages being similar to those reported by Huber [32].

As reported by Huber, the higher cost factor is of respiratory. However, the cost found in this study is higher than that estimated by Huber.

The main limitation regarding the estimates with using this information system is the dependency placed on the accurate recording of the patients' data in the EHR by the health professionals involved. Thus, the percentage of DM remains more or less constant and requires improvement in the recording of the codes.

\section{Conclusions}

Diabetes is characterized by the co-occurrence of other diseases, which has implications from a disease management point of view, and means a considerable increase in pharmaceutical consumption for this pathology and, as such, for pharmaceutical expenditure.

Additional studies are necessary for better characterization of the development of the disease and multimorbidity throughout life to establish intervention priorities.

\section{Acknowledgments}

The authors would like to thank members (Juan Bru, Inma Saurí and Laia Buigues) of the Pharmacoeconomics Office of the Health Departament of Valencian Government. The opinions expressed in this paper are those of the authors and do not necessary reflect those of the afore-named. Any errors are the authors' responsibility. We would also like to thank John Wright for the English editing.

\section{Funding}

This study was financed by a grant from the Fondo de Investigaciones de la Seguridad Social Instituto de Salud Carlos III, the Spanish Ministry of Health (FIS PI12/0037). 


\section{Authors' contributions}

DVC and LAE designed the study and drafted the manuscript. RUT applied the CRG software and carried out the first calculations of the results. MR and CSM rechecked and revised the statistical analysis. VCT compiled the prescription cost invoiced to the health system and prepared the databases before being analyzed. All authors read and approved the final manuscript.

\section{Authors' information}

David Vivas-Consuelo is a PhD Professor in the Research Centre for Health Economics and Management at Universitat Politècnica de València (Spain). Carla Sancho-Mestre and Vicent Caballer Tarazona are PhD candidates of the same university.

Ruth Usó-Talamantes is MD and PhD at Conselleria de Sanitat. Luis Alvis is an Health Economics at Universidad de Cartagena. Martin Romero is a MD, Director at Fundación Salutia Centro de investigaciones económicas, de gestión y tecnologías en salud, Bogotá, Colombia.

\section{Competing interests}

The authors declare that they have no competing interests.

\section{Consent for publication}

Not applicable.

\section{Ethics approval and consent to participate}

All information was made anonymous according to data protection regulations (Ley Orgánica 15/1999 and Real Decreto 1720/2007) and our observational study was approved by the Behavioural Research Ethics Board at the Generalitat Valenciana (Comité Ético de Investigación Clínica Corporativo de Atención Primaria de la Comunitat Valenciana, (EIC).

The need for consent to participate is deemed unnecessary since anonymised patient-level data was used in the study. The approval for use of the data was obtained from the Valencian Health Agency (reference number ID001036).

\section{Author details}

${ }^{1}$ Research Centre for Health Economics and Management, Universitat Politècnica de València, Edificio 7J, Cno de Vera s/n., 46022 Valencia, Spain. 2Universidad de Cartagena, Av. del Consulado \# Calle 30 No. 48 - 152, Cartagena, Bolívar, Colombia. ${ }^{3}$ Fundación Salutia, Carrera 71B \# 116A-12, PBX: [571] Bogotá D.C, Colombia. ${ }^{4}$ Valencian Health Department (Conselleria de Sanitat), General Directorate of Pharmacy and Pharmaceutical Products, Valencia, Spain.

\section{Received: 17 March 2016 Accepted: 10 August 2016} Published online: 17 August 2016

\section{References}

1. Whiting DR, Guariguata L, Weil C, Shaw J. IDF Diabetes Atlas: Global estimates of the prevalence of diabetes for 2011 and 2030. Diabetes Res Clin Pract. 2011;94:311-21. Available from: http://www.ncbi.nlm.nih.gov/ pubmed/22079683

2. Soriguer F, Goday A, Bosch-Comas A, Bordiu E, Calle-Pascual A, Carmena R, et al. Prevalence of diabetes mellitus and impaired glucose regulation in Spain: the Di@bet.es Study. Diabetologia. 2012;55:88-93. Available from: http://www.ncbi.nlm.nih.gov/pubmed/21987347

3. $\mathrm{WHO} \mid$ Rio Political Declaration on Social Determinants of Health. WHO. World Health Organization; 2011. Available from: http://www.who.int/ sdhconference/declaration/Rio_political_declaration.pdf?ua=1

4. Fortin M, Soubhi H, Hudon C, Bayliss EA, van den Akker M. Multimorbidity's many challenges. BMJ. 2007;334:1016-7. BMJ Group [cited 2016 Aug 4]. Available from: http://www.ncbi.nlm.nih.gov/pubmed/17510108

5. Valderas JM, Starfield B, Sibbald B, Salisbury C, Roland M. Defining comorbidity: implications for understanding health and health services. Ann Fam Med. 2009;7:357-63. [cited 2016 Aug 4]. Available from: http://www. ncbi.nlm.nih.gov/pubmed/19597174

6. Sundararajan V, Henderson T, Perry C, Muggivan A, Quan H, Ghali WA. New ICD-10 version of the Charlson comorbidity index predicted in-hospital mortality. J Clin Epidemiol. 2004:57:1288-94. Available from: http://www. ncbi.nlm.nih.gov/pubmed/15617955

7. Glynn LG, Valderas JM, Healy P, Burke E, Newell J, Gillespie P, et al. The prevalence of multimorbidity in primary care and its effect on health care utilization and cost. Fam Pract. 2011;28:516-23. [Internet]. 2011 [cited 2016 Aug 4]. Available from: http://www.ncbi.n/m.nih.gov/pubmed/21436204

8. Barnett K, Mercer SW, Norbury M, Watt G, Wyke S, Guthrie B. Epidemiology of multimorbidity and implications for health care, research, and medical education: a cross-sectional study. Lancet. 2012;380:37-43. [cited 2014 Nov 5] Available from: http://www.ncbi.nlm.nih.gov/pubmed/22579043

9. Holden L, Scuffham PA, Hilton MF, Muspratt A, Ng SK, Whiteford HA. Patterns of multimorbidity in working Australians. Popul Heal Metr. 2011;9:15. Available from: http://www.ncbi.n/m.nih.gov/pubmed/21635787

10. Starfield B. Threads and yarns: weaving the tapestry of comorbidity. Ann Fam Med. 2006;4:101-3. [cited 2016 Aug 4]. Available from: http://www. ncbi.nlm.nih.gov/pubmed/16569711

11. Abdul-Rahim HF, Holmboe-Ottesen G, Stene LCM, Husseini A, Giacaman R, Jervell J, et al. Obesity in a rural and an urban Palestinian West Bank population. Int J Obes. 2003;27:140-6. Available from: http://dx.doi.org/ 10.1038/sj.ijo.0802160

12. Boutayeb A, Boutayeb S, Boutayeb W. Multi-morbidity of non communicable diseases and equity in WHO Eastern Mediterranean countries. Int J Equity Heal. 2013;12:60. Available from: http://www.ncbi.nlm.nih.gov/pubmed/23961989

13. Teljeur C, Smith SM, Paul G, Kelly A, O'Dowd T. Multimorbidity in a cohort of patients with type 2 diabetes. Eur J Gen Pract. 2013;19:17-22. Available from: http://informahealthcare.com/doi/abs/10.3109/13814788.2012.714768, http://www.ncbi.nlm.nih.gov/pubmed/23432037

14. Hughes JS, Averill RF, Eisenhandler J, Goldfield NI, Muldoon J, Neff JM, et al. Clinical Risk Groups (CRGs): a classification system for risk-adjusted capitation-based payment and health care management. Med Care. 2004; 42:81-90. [cited 2016 Feb 29]. Available from: http://www.ncbi.nlm.nih.gov/ pubmed/14713742

15. Vivas-Consuelo D, Alvis-Estrada L, Uso-Talamantes R, Caballer-Tarazona V, BuiquesPastor L, Sancho-Mestre C. Multimorbidity Pharmaceutical Cost of Diabetes Mellitus. Value in Health. 2014;17:A341-2. Elsevier [cited 2016 Apr 21]. Available from: http://www.sciencedirect.com/science/article/pii/S1098301514026102

16. Inoriza JM, Pérez M, Cols M, Sánchez I, Carreras M. Análisis de la población diabética de una comarca : perfil de morbilidad, utilización de recursos, complicaciones y control metabólico. Aten Primaria. 2016;45. Available from: http://www.sciencedirect.com/science/article/pii/S0212656713001340

17. Vivas-Consuelo D, Usó-Talamantes R, Trillo-Mata JL, Caballer-Tarazona M, Barrachina-Martínez I, Buigues-Pastor L. Predictability of pharmaceutical spending in primary health services using Clinical Risk Groups. Health Policy. 2014;116:188-95. Available from: http://www.sciencedirect.com/science/ article/pii/S0168851014000256

18. Kho AN, Hayes MG, Rasmussen-Torvik L, Pacheco JA, Thompson WK, Armstrong $L L$, et al. Use of diverse electronic medical record systems to identify genetic risk for type 2 diabetes within a genome-wide association study. J Am Med Inform Assoc. 2016;19:212-8. [cited 2016 Feb 18]. Available from: http://www.pubmedcentral.nih.gov/articlerender.fcgi?artid=3277617\& tool=pmcentrez\&rendertype $=$ abstract

19. Prados-Torres A, Poblador-Plou B, Calderón-Larrañaga A, Gimeno-Feliu LA, González-Rubio F, Poncel-Falcó A, et al. Multimorbidity patterns in primary care: interactions among chronic diseases using factor analysis. PLOS One. 2012;7:e32190. Public Library of Science [cited 2016 Apr 21]. Available from: http://dx.doi.org/10.1371/journal.pone.0032190

20. Islam MM, Valderas JM, Yen L, Dawda P, Jowsey T, McRae IS. Multimorbidity and comorbidity of chronic diseases among the senior Australians: prevalence and patterns. PLoS One. 2014;9:e83783. Public Library of Science [cited 2016 Mar 25]. Available from: http://dx.doi.org/10.1371/journal.pone. 0083783

21. Fortin M, Bravo G, Hudon C, Lapointe L, Dubois MF, Almirall J. Psychological distress and multimorbidity in primary care. Ann Fam Med. 2006;4:417-22. Available from: http://www.ncbi.nlm.nih.gov/pubmed/17003141

22. Nuttall M, van der Meulen J, Emberton M. Charlson scores based on ICD-10 administrative data were valid in assessing comorbidity in patients undergoing urological cancer surgery. J Clin Epidemiol. 2006;59:265-73. Available from: http://www.ncbi.n/m.nih.gov/pubmed/16488357

23. Klompas M, Eggleston E, McVetta J, Lazarus R, Li L, Platt R. Automated detection and classification of type 1 versus type 2 diabetes using electronic health record data. Diabetes Care. 2013;36:914-21. Available from: http://www.ncbi.nlm.nih.gov/pubmed/23193215

24. Alonso-Moran E, Orueta JF, Fraile Esteban Jl, Arteagoitia Axpe JM, Luz Marques Gonzalez M, Toro Polanco N, et al. The prevalence of diabetesrelated complications and multimorbidity in the population with type 2 
diabetes mellitus in the Basque Country. BMC Public Health. 2014;14. Available from: http://www.ncbi.nlm.nih.gov/pmc/articles/PMC4197247/

25. Pantalone KM, Hobbs TM, Wells BJ, Kong SX, Kattan MW, Bouchard J, et al. Clinical characteristics, complications, comorbidities and treatment patterns among patients with type 2 diabetes mellitus in a large integrated health system. BMJ open diabetes Res Care. 2015;3:e000093. Available from: http://www.pubmedcentral.nih.gov/articlerender.fcgi?artid=4513350\&tool= pmcentrez\&rendertype=abstract

26. Alonso-Moran E, Satylganova A, Orueta JF, Nuno-Solinis R. Prevalence of depression in adults with type 2 diabetes in the Basque Country: relationship with glycaemic control and health care costs. BMC Public Health. 2014;14. Available from: http://bmcpublichealth.biomedcentral.com/ articles/10.1186/1471-2458-14-769

27. Kilzieh N, Rastam S, Maziak W, Ward KD. Comorbidity of depression with chronic diseases: a population-based study in Aleppo, Syria. Int J Psychiatry Med. 2008;38:169-84. Available from: http://www.ncbi.nlm.nih.gov/pubmed/ 18724568

28. Almawi W, Tamim H, Al-Sayed N, Arekat MR, Al-Khateeb GM, Baqer A, et al. Association of comorbid depression, anxiety, and stress disorders with Type 2 diabetes in Bahrain, a country with a very high prevalence of Type 2 diabetes. J Endocrinol Invest. 2008;31:1020-4. Available from: http://www.ncbi.nlm.nih.gov/pubmed/19169060

29. Giralt Muiña P, Gutiérrez Ávila G, Ballester Herrera MJ, Botella Romero F, Angulo Donado JJ. Prevalencia de diabetes y diabetes oculta en adultos de Castilla-La Mancha. TITLEREVISTA. 2011;137:484-90. Available from: http://zl.elsevier.es/es/revista/medicina-clinica-2/prevalencia-diabetesdiabetes-oculta-adultos-castilla-la-mancha-90028329-originales-2011

30. Mata-Cases $M$, Roura-Olmeda P, Berengué-Iglesias $M$, Birulés-Pons $M$, Mundet-Tuduri X, Franch-Nadal J, et al. Fifteen years of continuous improvement of quality care of type 2 diabetes mellitus in primary care in Catalonia, Spain. Int J Clin Pract. 2012;66:289-98. Available from: http://www.pubmedcentral.nih.gov/articlerender.fcgi?artid=3584513\& tool=pmcentrez\&rendertype $=$ abstract

31. Egede LE, Gebregziabher M, Zhao Y, Dismuke CE, Walker RJ, Hunt KJ, et al. Differential Impact of Mental Health. 2015;21:535-44. Available from: http:// www.ncbi.nlm.nih.gov/pubmed/26295353

32. Huber CA, Diem P, Schwenkglenks M, Rapold R, Reich O. Estimating the prevalence of comorbid conditions and their effect on health care costs in patients with diabetes mellitus in Switzerland. Diabetes Metab Syndr Obes. 2014;7:455-65. Dove Press [cited 2016 Aug 4]. Available from: https:/www. dovepress.com/estimating-the-prevalence-of-comorbid-conditions-and-theireffect-on-h-peer-reviewed-article-DMSO

\section{Submit your next manuscript to BioMed Central and we will help you at every step:}

- We accept pre-submission inquiries

- Our selector tool helps you to find the most relevant journal

- We provide round the clock customer support

- Convenient online submission

- Thorough peer review

- Inclusion in PubMed and all major indexing services

- Maximum visibility for your research

Submit your manuscript at www.biomedcentral.com/submit

) Biomed Central 